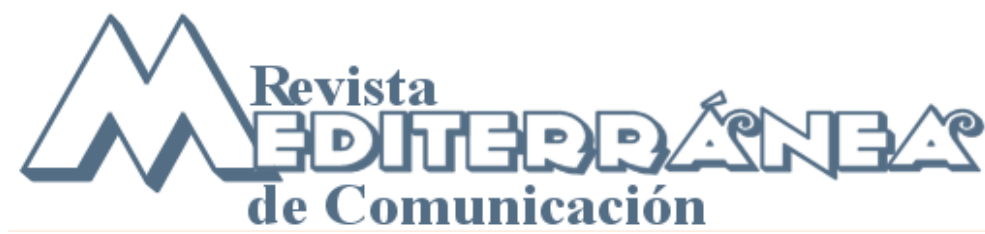

\title{
Prensa local e infraestructuras. La interesada marginación del periodismo medioambiental.
}

\section{Local press and infrastructures. Environmental journalism selfishly marginalization}

\author{
Dr. Samuel Toledano Buendía \\ Investigador de la Sociedad Latina de Comunicación Social. \\ Universidad de La Laguna. Tenerife. Spain. \\ samueltoledano@hotmail.com
}

\begin{abstract}
Resumen
Conscientes de la dificultad para encuadrar muchas informaciones dentro de un área especializada del periodismo, este artículo analiza cómo la polémica construcción de un puerto industrial en Tenerife es abordada por el periódico de mayor difusión de la isla. A la vista de los elementos políticos, económicos, sociales y medioambientales que confluyen en el proyecto, se opta por hacer un análisis crítico del discurso, como método más adecuado para detallar los recursos del medio para trasladar al lector una realidad afín a los sectores políticos y económicos que defienden esta construcción. Se evidencia que la premeditada decisión de marginar la perspectiva medioambiental garantiza el marco idóneo para ocultar todas las manipulaciones orientadas a que la opinión pública apruebe el puerto.
\end{abstract}

\section{Palabras clave}

Prensa, periodismo, desarrollo, España

\section{Abstract}

Given that the difficulty to classify many informations in a journalism specialized area, this article analyses how a controversial industrial port project in Tenerife is covered by the island biggest selling newspaper. Considering the political, economical, social and environmental factors involved in this project, we choose a critical discourse analysis as the best methodological way to show the media resources for showing the reader a reality wanted by the political and economical sectors which support this public work. It is proved that the selfishly marginalization of the environmental perspective guaranteed the best context to hide all the manipulations created to gain the public opinion support to the port.

\section{Key Words}

Press, journalism, development, Spain.

\footnotetext{
Forma de citar este artículo: Toledano Buendía, S. (2010): " Prensa local e infraestructuras. La interesada marginación del periodismo medioambiental", en Revista Mediterránea de comunicación, 1, pp. 51-70. Recuperado el día de mes de año (añadir enlace)
} 
Sumario 1. Introducción. 2. El discurso de un periódico local. 3. El periodismo especializado. 3.1. El periodismo medioambiental. 4. La información de una obra. 4.1. Iniciativa Legislativa Popular contra el proyecto 4.2. Asamblea empresarial en defensa de las infraestructuras. 4.3. Constitución de la Asamblea por Tenerife. 4.4. Manifestación contra el puerto de Granadilla. 4.5. Rechazo parlamentario a la Iniciativa Legislativa Popular. 5. La opinión de una obra. 6. Consideraciones finales. 7. Bibliografía. 8. Notas.

Summary 1. Introduction. 2. The local newspaper discourse. 3. Specialized journalism. 3.1. Environmental journalism. 4. The information of a public work. 4.1. People`s legislative initiative against the project 4.2. Business meeting reclaiming infrastructures. 4.3. Assembly for Tenerife constitution. 4.4. Demonstration against Granadilla port. 4.5. People`s legislative initiative rejection. 5. The opinion of a public work. 6. Final statements. 7. Bibliography. 8. Notes.

\section{Introducción}

Compaginar el crecimiento económico con el respeto al medioambiente se ha constituido como una de las principales prioridades de sectores sociales que, especialmente en los países occidentales, han denunciado el daño irreparable de las décadas de ilimitado desarrollo y han exigido un avance hacia una sostenibilidad que evite la destrucción del planeta al tiempo que garantice ciertas comodidades del actual modelo de vida.

El concepto de desarrollo sostenible, fruto del interés por compaginar ambos intereses, supone, sin embargo, un terreno de frecuente fricción, al no delimitarse claramente el punto en el que finaliza uno y empieza el otro. Este terreno se configura así como un espacio propicio para el debate político, tanto por las diferentes perspectivas ideológicas que defienden los partidos, como por la obligación de las instituciones públicas de buscar los intereses globales de la sociedad, por encima de los intereses particulares de los sectores implicados.

Con cierta lógica, el debate suele alcanzar unas mayores dimensiones cuantos mayores son los intereses que se ponen en juego. Así, serán las grandes actuaciones en el territorio las que acaparen mayor atención, gracias a los amplios beneficios que pueden generar al conjunto de la población y a los grandes daños que supondrían para un territorio concreto. Ambas visiones, obviamente, se contradicen y se presentan públicamente como defensoras del bien común, unas acudiendo al desarrollo económico y otras a un entorno físico saludable para sus habitantes.

En España, junto a la destrucción de la costa por su uso turístico y residencial, las grandes infraestructuras han marcado en numerosas ocasiones el debate político, como los proyectos de la central nuclear de Lemoniz en el País Vasco, el embalse de Itoiz en Navarra o el trasvase del Ebro a la cuenca del Segura. El debate, al tratarse de proyectos con un periodo de estudio, discusión y ejecución muy amplio, supone un foco continuo de interés informativo donde las diferentes posturas intentan ganarse el respaldo de la opinión pública. 
En Canarias, con un territorio limitado, marcado por una alta densidad de población y numerosos parajes naturales protegidos, este enfrentamiento constituye un elemento de continua actualidad informativa, con grandes o simbólicas infraestructuras que son rechazadas por colectivos sociales y vecinales. Así, sin una postura clara de los partidos políticos, la sociedad canaria parece haber escogido la conservación del territorio como uno de los elementos de mayor importancia, en vista, al menos, de las iniciativas legislativas populares o de las manifestaciones multitudinarias de los últimos años frente a tendidos eléctricos, radares, autovías u otras infraestructuras ligadas al transporte.

El proyecto del puerto industrial de Granadilla, al igual que otras infraestructuras polémicas, ha generado un fuerte rechazo social, originando manifestaciones y denuncias ante las diferentes estancias autonómicas, nacionales y europeas, convirtiéndose así en un tema de actualidad durante varios años.

Junto al evidente interés económico de dicho proyecto, limitado al ámbito local, existe también un interés medioambiental, en la medida en que afecta a un paraje con un alto valor natural. Así, los medios se presentan como los actores más cualificados para presentar los elementos que permitan comprender los intereses en juego, teniendo que optar desde un primer momento por enfocar este asunto desde una perspectiva de periodismo especializado, con las posibles implicaciones que ello conlleva.

El análisis que hacemos del periódico El Día y su cobertura a cinco fechas concretas en 2004, año que registró una gran acumulación de acontecimientos relativos al puerto de Granadilla, nos debe revelar la posible existencia de una sección de información medioambiental y el modo concreto de exponer este proyecto a los lectores. Como consecuencia, la imagen de los poderes políticos y económicos locales y la de los movimientos sociales, así como la repercusión de sus planteamientos sobre esta infraestructura, dependerá también en gran medida de los medios de comunicación y, en este caso, del periódico de mayor difusión de Tenerife.

\section{El discurso de un periódico local}

Conscientes del poder que atesoran los medios de comunicación de masas para influir en la opinión de los ciudadanos, se ha optado por analizar un medio escrito, aprovechando el consenso que hay sobre la mayor calidad que hay en la prensa frente a las radios y televisiones. Las razones de este argumento, no extenso de polémica, están en el mayor espacio y tiempo que tiene el profesional de un periódico para elaborar una información frente a los redactores de radio y televisión, siempre supeditados a la inmediatez de sus medios. En un escenario ideal, esto garantizaría que ante un tema tan polémico y con tantos intereses en juego, El Día -periódico seleccionado por ser el de mayor difusión de la isla- ofreciera un tratamiento mucho más amplio y contextualizado.

Aunque somos conscientes de que la construcción de este puerto sigue siendo un tema de plena actualidad y que en el trasfondo existe un debate político y económico, creemos necesario acotar el estudio a los elementos más visibles de este enfrentamiento entre 
partidarios y detractores de esta infraestructura, donde se nos garantice, además, un mayor caudal informativo. De esta forma, acudimos al año 2004 y a cinco fechas que consideramos clave en este proyecto, relacionadas todas con debates parlamentarios, manifestaciones y cumbres empresariales.

Nuestro estudio se concreta así en esas cinco fechas, analizando cada una durante un periodo de dos semanas, una antes y otra después del acontecimiento. Esto nos ofrece un mínimo de 75 días analizados y de 115 páginas estudiadas, incluyendo aquí las portadas de los periódicos, los titulares y elementos destacados de las noticias así como el contenido de las mismas.

Para dicho análisis aprovecharemos nuestra participación ordinaria en los medios de comunicación, y en concreto en medios locales -agencias y periódicos-, lo que nos permitirá interpretar algunos elementos analizados, pero siempre partiendo de un paradigma alternativo, tal y como lo entiende McQuail (2000: 93):

- Visión crítica de la sociedad y rechazo de la neutralidad de valores.

- Rechazo del modelo de transmisión de la comunicación.

- Visión no determinista de las tecnologías y mensajes mediáticos.

- Metodologías cualitativas y culturales.

- Preferencia por las teorías culturales o político-económicas.

- Preocupación por las desigualdades y las fuentes de oposición en la sociedad.

De forma más concreta, buscaremos un enfoque eminentemente cualitativo, puesto que más allá de los datos cuantificables, centraremos el estudio en el discurso y en el análisis de contenido. Así, y aunque en un principio el análisis del contenido se nutre de métodos cuantitativos, hoy se llega incluso a entender que "no puede no ser sino cualitativo, condición a la que no puede sustraerse, puesto que ninguna metodología de Análisis de Contenido puede dejar de afincarse en un marco teórico que especifique las categorías analíticas empleadas" (Piñuel y Gaitán, 1995: 517-518).

"Análisis de contenido se llama actualmente, en sentido amplio, al conjunto de procedimientos interpretativos y de técnicas de comprobación y verificación de hipótesis aplicados a productos comunicativos (mensajes, textos o discursos), o a interacciones comunicativas que, previamente registradas, constituyen un documento, con el objeto de extraer y procesar datos relevantes sobre las condiciones en que se han producido, o sobre las condiciones que puedan darse para su empleo posterior" (Piñuel y Gaitán, 1995: 511).

Buscaremos así esos productos comunicativos e intentaremos saber cómo se han producido, adentrándonos en el estudio interdisciplinario de las noticias y el discurso. Tomaremos los diferentes puntos expresados por Van Dijk, uno de los referentes en el análisis del discurso: esquema de las noticias, estilo y la retórica, cognición social y contextos socioculturales.

"[...] el estudio de los informes sobre noticias en la prensa es uno de los cometidos más importantes de la investigación analítico-discursiva sobre los medios. [...] Este propósito está justificado cuando nos damos cuenta de lo importantes que son las noticias en nuestra vida cotidiana. La mayor parte de nuestro conocimiento social y político y de nuestras opiniones sobre el mundo proceden de las 
docenas de reportajes e informaciones que vemos o leemos cada día. Es probable que no haya ninguna otra práctica discursiva, además de la conversación cotidiana, en la que se tome parte con tanta frecuencia y por parte de tanta gente como las noticias que aparecen en la prensa o en la televisión" (Van Dijk, 1993: 137).

Compartiendo el argumento de la imposibilidad de separar las dimensiones académicas y políticas en cualquier conflicto científico y de que los conflictos epistemológicos son siempre políticos (León, 2010) nuestra atención se centrará en el discurso, al configurarse como el espacio idóneo para las diferentes estrategias manipuladoras que, en manos de los medios de comunicación de masas, pretenden moldear a los receptores acudiendo a informaciones incompletas, valores sociales, elementos emocionales o los estatus de las fuentes (Van Dijk, 2006: 375). Nos afianzamos así por una "perspectiva crítica"1, analizando el discurso "con una actitud" en lo que viene a caracterizar la propuesta de análisis crítico del discurso (ACD) definido por Van Dijk:

\begin{abstract}
"Se centra en los problemas sociales, y en especial en el papel del discurso en la producción y en la reproducción del abuso de poder o de la dominación. Siempre que sea posible, se ocupará de estas cuestiones desde una perspectiva que sea coherente con los mejores intereses de los grupos dominados. Toma seriamente en consideración las experiencias y las opiniones de los miembros de dichos grupos, y apoya su lucha contra la desigualdad. Es decir, la investigación realizada mediante el ACD combina lo que, de forma tal vez algo pomposa, suele llamarse "solidaridad con los oprimidos» con una actitud de oposición y disidencia contra quienes abusan de los textos y las declaraciones con el fin de establecer, confirmar o legitimar su abuso de poder. A diferencia de otros muchos saberes, el ACD no niega sino que explícitamente define y defiende su posición sociopolítica. Es decir, el ACD expresa un sesgo, y está orgulloso de ello" (Van Dijk, 2003: 144).
\end{abstract}

\title{
3. El periodismo especializado
}

Con cierta estatus de privilegio, los medios de comunicación de masas tienen un monopolio de facto, puesto que siguen siendo los referentes a los que acuden los ciudadanos para informarse, creando un círculo de oferta y demanda provechoso para el medio.

Sin embargo, estos medios tienen la obligación de ir más allá de la mera transmisión de acontecimientos para entrar también en las otras dos funciones del periodismo: formar y entretener. El periodismo se configura así como una profesión especializada que informa, forma y entretiene sobre la generalidad de la realidad.

El problema lo encontramos cuando la realidad se parcela en múltiples áreas que, a su vez, requieren ser informadas con un conocimiento mucho más exhaustivo. Hablamos así de un periodismo especializado, y convertido en "instrumento mediante el cual los medios

\footnotetext{
${ }^{1}$ Wodak considera que la noción de crítica "ha de entenderse como el resultado de tomar cierta distancia respecto de los datos, enmarcar estos en lo social, adoptar explícitamente una postura política y centrarse en la autocrítica, como corresponde a un estudioso que investiga" (2003: 29).
} 
de comunicación abordan los problemas derivados de la especialización del conocimiento en general, su desconexión con la sociedad y la consiguiente pérdida de una visión global de la información" (Sanmartí, 2003: 7).

"El PE intenta, pues, dar respuesta a los retos informativos planteados por la sociedad libre, democrática y moderna. Es decir, un mundo muy complejo, tremendamente interrelacionado y dispuesto a alcanzar nuevas metas, conectadas algunas de ellas tanto a los contenidos como a los medios y las audiencias" (Sanmartí, 2003: 8).

Con una realidad fragmentada y con los medios haciendo uso, teóricamente, del periodismo especializado para dar respuesta a esos retos de la sociedad libre, democrática y moderna, los periodistas se presentan como "profesionales con gran capacidad de análisis y profundos conocimientos en sus respectivos campos informativos". Su trabajo publicado será el "indicativo palpable de la libertad e independencia del medio, a la hora de tratar los diferentes temas de la actualidad" (Seijas, 2003: 99).

\subsection{El periodismo medioambiental}

Intermediarios de una amplia realidad que no puede alcanzar directamente la persona, los medios de comunicación se afianzan como unos actores de gran relevancia para aquellos que exigen que el espacio natural esté siempre por encima del desarrollo económico y, de forma más consensuada, para los que abogan por un equilibrio entre ambas propuestas.

De hecho, la necesidad de preservar el medio ambiente como garantía de supervivencia humana se ha visto favorecida por la labor de los medios de comunicación, que han colaborado activamente al informar sobre las distintas agresiones medioambientales y las actuaciones llevadas a cabo para su defensa, tal y como reconoce el "Informe sobre el Estado del Medio Ambiente" elaborado por el programa de Naciones Unidas para el Medio Ambiente (Esteve y Fernández del Moral, 1999: 295). Otros estudios revelan igualmente los efectos positivos que la sola publicación de asuntos mediambientales tiene en la opinión pública sobre los grupos ecologistas y las causas que defienden (Vliegenthart et al.: 2009).

El problema, según recogen muchos expertos, es que pese a los progresos que se han hecho en la información ambiental, el derecho a recibir este tipo de noticias no está garantizado en los medios de comunicación (Calvo, 1996: 119). Así, hay una "demanda de información ambiental que la prensa diaria no está satisfaciendo", debido o reflejado en el escaso número de periodistas que en España están dedicados de pleno a este tipo de información o a que "no exista ni una sola sección ambiental en los diarios españoles", lo que obliga a publicar todas estas informaciones en las áreas de local o sociedad (Zorrilla, 1996: 62).

A esta dificultad se suma la dependencia de los periodistas que voluntariamente se dedican a cubrir esas informaciones, más por iniciativa que por petición del medio o la sección, como constatan algunos de los profesionales dedicados a esa labor: "La 
evolución de la información ambiental en Canal Sur ha sido similar a la de otros medios de comunicación. Dentro de la socorrida sección de Sociedad y Cultura se hace Medio Ambiente. La ventaja que había aquí desde un principio es que existía una persona, que era yo, que se ocupaba de estos temas y, por lo tanto, había una información continua" (Montaño, 1999).

Para añadir más confusión a la ubicación temática del periodismo medioambiental, en él entran asuntos relativos a los residuos, agua, transportes, construcción, administración, desarrollo o turismo, susceptibles de ser ubicadas en otras secciones. En función de estos temas, Josep María Sanmartí opta por dividir la información en cinco subgéneros:

1. Ambientalista. Se preocupa de la contaminación, los sistemas de depuración o el transporte y el tráfico.

2. Conservacionista. Trata de la preservación y conocimiento de la flora y fauna, es decir de los ecosistemas, de las especies de animales, de los parques naturales, del ocio y el turismo.

3. Científico y técnico. Habla de los progresos científicos y técnicos aplicados al medio ambiente.

4. Energético. Se circunscribe a los temas relacionados con la energía del tipo que sea.

5. Ecopolítico. Examina fundamentalmente la política medioambiental de las distintas administraciones, especialmente tras el acceso al poder de partidos ecologistas y la asunción de sus propuestas por partidos tradicionales y gobiernos (Sanmartí, 2003: 132).

Independientemente del tipo de subgénero que se realice, pero especialmente en el conservacionista, surgirá siempre alguna tensión entre los partidarios de mantener un espacio natural y los que consideran que es necesario actuar en ese lugar para proporcionar unos intereses a la generalidad de la población.

En ese punto, el periodismo conservacionista pondrá al redactor en el dilema de saber que su trabajo puede ser muy lúcido y agradecido con una gran repercusión popular pero que, al mismo tiempo, puede ser objeto de fuertes polémicas porque se le acusa de frenar el desarrollo de ciertas comarcas o poblaciones (Sanmartí, 2003: 132).

En el debate entre partidarios y detractores de estos proyectos, la postura profesional de los medios de comunicación y sus periodistas consiste en buscar un equilibrio entre las diferentes opiniones para ofrecer igualdad de oportunidades a los defensores del espacio natural y a los del desarrollo. Sería ideal, además, la presencia de fuentes que, más allá de ofrecer una visión política, realicen aportaciones rigurosas a la información que reciba el lector. 
Sin embargo, el periodista que trabaja cubriendo estos asuntos debe saber que, aunque intente ofrecer una postura intermedia, evitando dar su opinión sobre el proyecto, su trabajo será objeto de críticas por ambas partes:

\begin{abstract}
"Los grupos industriales y algunos científicos acusan de informar sobre los riesgos potenciales de modo sesgado, sensacionalista y no tecnológico y culpan a la prensa de crear un temor injustificado ante la tecnología y una desconfianza sobre las prácticas industriales. Otros grupos de científicos, los ambientalistas y los defensores de los consumidores acusan a la prensa de confiar exclusivamente y de modo injusto en 'establishment' y de ocultar información que podría cuestionar a las industrias locales" (Calvo, 1996: 119-120).
\end{abstract}

Que el periodista sea "acusado" de realizar una información parcial sobre un asunto es algo que entra dentro de la lógica, especialmente cuando existen enfrentamientos enconados entre varias partes, y éstas, de manera susceptible, se sienten tratadas de diferente manera. Las quejas, planteadas a posteriori, no deben repercutir en la labor que todo periodista profesional hace, primando la objetividad y el respeto e igualdad en el tratamiento que se haga de cada parte. Pero la realidad demuestra con excesiva frecuencia que hay una clara "disfunción" en el informador medioambiental y que no es otra que el "partidismo":

\footnotetext{
"Determinadas noticias poseen una clara intencionalidad partidista a favor de ciertas siglas políticas o ideológicas o de intereses comerciales o industriales. En este sentido, cabe denunciar las distintas presiones a las que se ven sometidos, a veces, los informadores medioambientales por parte de políticos, empresarios o instituciones interesadas en velar por su imagen pública" (Esteve y Fernández del Moral, 1999: 303).
}

Conocemos que las presiones no suelen ejercerse de forma directa sobre el periodista, sino que van dirigidas a los responsables del medio, que ante argumentos de retirada de publicidad por las grandes empresas optan por evitar noticias perjudiciales para las mismas. Sin embargo, esta forma de actuar, aún presente, se ve sustituida lentamente por una autocensura o por el fácil recurso a los gabinetes de comunicación. Éstos, conscientes de la tendencia de los profesionales de obviar incluso el necesario contraste de las notas de prensa, y no ampliar la noticia con otras fuentes, se adelantan a posibles críticas e informan, casi en primicia, de sucesos, accidentes o percances.

La actividad de los gabinetes, en cualquiera que sea su ámbito, intenta garantizar la mejor imagen posible, lo que obviamente implica que la acción de comunicación que desarrollan "no puede improvisarse: debe ser precedida de una fase de concepción a la que seguirán una planificación y organización cuidada" (Baamonde, 2010).

La predominante pasividad y autocensura del periodismo actual origina que, tarde 0 temprano, el gabinete de comunicación se convierta en la única fuente informativa -con sus intereses definidos- y que sus notas de prensa sirvan "en unas ocasiones como argumento principal sobre el que se apoyan todas las noticias, y en otras, como referencia para evaluar las actuaciones que se desarrollaban en la zona". Aunque la cita de Elías (2002) se refiere al accidente medioambiental de Aznalcóllar, donde los medios de 
información fueron manipulados por el $\mathrm{CSIC}^{2}$, parece evidente que, incluso hablando de un periodismo especializado, los medios se "identifican" con los informes y posturas oficiales del gabinete de prensa.

Si tomamos lo analizado por Elías así como lo señalado por otros autores en relación a lo publicado sobre la conferencia de las Naciones Unidas sobre el cambio climático celebrada en Bali (Lorente et al, 2009), nos hallamos ante la paradójica sensación de que se va afianzando un periodismo especializado en medioambiente que, sin embargo, es utilizado por los medios según sus intereses. Entendemos así que, en lugar de garantizar una defensa de la naturaleza, este periodismo acabe como un instrumento de manipulación política (Elías, 2002) o que reconduzca aspectos como el desarrollo sostenible hacia la "mitigación de los impactos mensurables en el entorno natural" y oculte lo que no le interesa: "Su dimensión social, económica y cultural del modelo de desarrollo asentado en el crecimiento y explotación sistemática de los recursos naturales que lo ha provocado" (Lorente et al, 2009).

\section{La información de una obra}

El puerto industrial de Granadilla de Abona es un proyecto planteado por la Autoridad Portuaria de Santa Cruz de Tenerife, justificado con varios argumentos, pero centrados todos en que esta infraestructura podría diversificar la economía de la isla y del archipiélago, dependiente en un alto porcentaje del turismo. Así, el planteamiento de esta entidad, apoyada por los líderes políticos y económicos, ahonda en el uso de este puerto como centro internacional de distribución de contenedores que, además, crearía numerosos puestos de trabajo, permitiría la introducción de gas en la isla y, sobre todo, acabaría con las limitaciones y el déficit de competitividad del puerto de la capital de la isla.

Esta infraestructura ha contado con el apoyo de los empresarios de la isla y de Canarias, agrupados en organizaciones como la Cámara de Comercio de Santa Cruz de Tenerife o la Confederación Organizaciones Empresariales de Tenerife. También ha tenido el respaldo de los partidos Coalición Canaria y el Partido Popular, mientras que el otro gran partido de la isla, el PSOE, se ha mantenido en una posición ambigua, que ha oscilado entre el completo apoyo al proyecto, incluido el Ayuntamiento de Granadilla, gobernado por los socialistas ${ }^{3}$, y un frontal rechazo, pasando también por una apuesta intermedia que defendía un puerto más pequeño.

\footnotetext{
${ }^{2}$ Elías argumenta que el gabinete de comunicación del Consejo Superior de Investigaciones Científicas, tras la rotura de la presa de Aznalcóllar el 25 de abril de 1998, llevó a cabo un estrategia que logró que todos los medios de comunicación terminaran "identificados" con sus informes, "hasta tal punto que los procesos de retirada de lodos que no se habían realizado siguiendo los consejos del CSIC son denunciados por los medios de comunicación".

${ }^{3}$ En 2004, año analizado en este estudio, el PSOE gobernaba. Perdió la alcaldía en 2007 en virtud de un pacto entre Coalición Canaria y Alternativa Si se puede por Granadilla, cuyo principal punto de acuerdo era el rechazo a esta infraestructura.
} 
Los que se han opuesto a esta infraestructura han defendido que el puerto de Santa Cruz de Tenerife puede crecer mucho más y que sus instalaciones se están infrautilizando para limitarlo a ser destino de cruceros y trasladar así todo el tráfico de mercancías al proyecto de Granadilla, donde además se ha producido una especulación de los terrenos colindantes, al margen de los beneficios económicos que ya se lograrían sólo con la construcción de esta infraestructura.

Sin embargo, los argumentos que han conseguido paralizar la obra durante los últimos años radican en los irreparables daños que el puerto causaría en sebadales ${ }^{4}$ y otros elementos de la flora y fauna del litoral. Con ese argumento se presentó en 2004 en el Parlamento de Canarias una Iniciativa Legislativa Popular (ILP) avalada por más de 50.000 firmas que solicitaba la declaración de la Reserva Natural Especial del Litoral Noroeste de Granadilla, y cuya tramitación fue rechazada en enero de 2005 con los votos del PP y CC.

Colectivos ecologistas, asociaciones vecinales, sindicatos y partidos políticos extraparlamentarios, especialmente de izquierda o independentistas, han expresado su clara oposición a este proyecto, así como un gran sector de la sociedad, reflejada como mínimo en las más de 50.000 personas que avalaron la ILP y en las manifestaciones realizadas previamente.

Aunque este proyecto ha generado información de forma constante durante los últimos años, ha sido 2004 el año de mayor relevancia informativa, propiciada por lo que se suponía que era el inminente comienzo de su construcción. Así, partidarios y detractores del puerto organizaron algunos actos que, junto a la presentación de la ILP y su posterior rechazo, constituyen las fechas más destacadas de este debate social.

\subsection{Iniciativa Legislativa Popular contra el proyecto}

La presentación de la Iniciativa Legislativa Popular para la declaración como Reserva Natural Especial del Litoral Noroeste de Granadilla el 20 de abril de 2004 es respaldada por más de 50.000 firmas que los colectivos ecologistas habían recogido durante los anteriores meses. Sin embargo, previamente, El Día ya incluía informaciones relativas a este proyecto, comentadas frecuentemente en editoriales y columnas.

En estos días previos, el periódico recoge en un titular la opinión de la Asociación Unión de Exportadores Canarias de que "El futuro del comercio entre Tenerife y África depende del puerto de Granadilla" (14-04-04, pp. 1 y 41) , mientras que días después podemos

\footnotetext{
${ }^{4}$ El sebadal es una especie marina que se ha convertido en un emblema en la lucha contra el puerto de Granadilla. En la zona donde se plantea esta construcción existe una de las mayores reservas de Canarias que se ha intentado proteger $-y$ el ecosistema que de él depende- a través de iniciativas legislativas populares rechazadas por el Parlamento.

${ }^{5}$ Todas las referencias hemerográficas pertenecen al periódico El Día, por lo que se opta por señalar exclusivamente las fechas y las páginas de donde se extrae la información, sin repetirlas luego ni en las notas al pie de página ni al final del artículo.
} 
leer la noticia de que "Las Palmas gana terreno a Tenerife como plataforma de comercio internacional" (17-04-04, p. 38), con un despiece que lo vincula al polémico puerto: "Pendientes de Granadilla".

Más escasas son las noticias contrarias al puerto, y sólo se encuentran algunas como las peticiones ecologistas de reunirse con el Ministerio de Medio Ambiente o el envío a Europa de un escrito contra el proyecto por la asociación ecologista ATAN. Esta última información, recogida brevemente en la sección de Tenerife, compite el mismo día con otra de la sección de Economía: "Puertos de Tenerife adjudicará las obras de Granadilla este año" (19-04-04, pp. 12 y 29). Un día después, el periódico destaca, con una referencia en portada, que la "CEOE exige una Zona Franca para el puerto de Granadilla", dando no sólo por hecha la construcción de esta infraestructura, sino exigiendo incluso las condiciones fiscales de su uso (20-04-04, pp. 1 y 41).

Mucho más significativo es la cobertura del periódico a la presentación de la ILP. Así, en la cuarta y última página de la sección de Economía leemos que "EI PSOE repite que hay que potenciar al máximo el puerto de Santa Cruz" y que dirigentes socialistas "insistieron" en su posición. Al margen de que no se destaca sus críticas al puerto de Granadilla, esta noticia relega al inferior de la página el hecho más trascendente por su significativo apoyo: "La iniciativa popular contra el puerto de Granadilla suma un total de 56.000 firmas". Ninguna de las dos noticias es mencionada en la portada del periódico (21-04-04, pp. 41 y 42).

Los empresarios, en vista de esta iniciativa ciudadana, comienzan su campaña de declaraciones y comunicados pidiendo la construcción del puerto: "La Cámara tinerfeña exige el inicio de las obras del puerto de Granadilla", "CEOE alerta del sobre coste del tráfico de contenedores y denuncia que es más caro mover mercancías en Tenerife que en Las Palmas" o "Parar el Puerto de Granadilla llevaría a Tenerife a la "decadencia económica". Leyendo el contenido de estas noticias, todas abriendo la sección y con sus correspondientes huecos en portada, vemos que las tres noticias abordan reclamaciones de la Cámara de Comercio, que posteriormente apoya la CEOE y que luego nuevamente la Cámara de Comercio respalda lo dicho por la CEOE, en una dinámica de apoyo mutuo auspiciada por el medio (1-05-04, pp.1 y 41; 5-05-04, pp. 1 y 38; y 7-05-04, pp. 1 y 39).

\subsection{Asamblea empresarial en defensa de las infraestructuras}

La reunión empresarial que el 28 de junio de 2004 se celebró en el recinto ferial de Tenerife tenía como declarado objetivo presionar a las administraciones públicas para construir las infraestructuras -según ellos demandadas por la isla-. Anunciada y presentada como si de una feria se tratara ${ }^{6}$, los diferentes medios de comunicación garantizaron desde días antes una amplia cobertura al evento.

\footnotetext{
${ }^{6}$ Diversas organizaciones e instituciones participaron en un evento que, con una campaña de comunicación similar a la de una feria convencional, se defendieron, con presentaciones y material informativo, las diferentes infraestructuras demandas. Así, y frente a una elevada presencia de empresarios y medios informativos, se observaba una estrategia antes, durante y después del acto, donde "la interactividad y el
} 
Con "El puerto de Granadilla generará 20.000 empleos" el periódico decide encabezar su edición del día 23, en referencia a un estudio encargado por la Autoridad Portuaria de Tenerife a "reputados expertos" de una "prestigiosa firma nacional" (23-06-04, pp. 1 y 44). Ya dos días después, bajo el titular "El progreso económico de Tenerife se frenará si no mejoran sus puertos", descubrimos el nombre de esa "prestigiosa firma" (Centro de Estudios Económicos Tomillo S.L.) cuyo "prestigio" siempre es susceptible de subjetividad así como el uso parcial que de su informe hace la Autoridad Portuaria o el periódico, en la medida en que sólo se publican aspectos positivos y argumentos que defienden que hay que construir más para crecer más (25-06-04, p. 44).

Con el objetivo puesto en la futura asamblea de empresarios, vemos titulares como "Alerta empresarial a los políticos tinerfeños" y "El empresariado exige a los políticos que eviten un parón económico de Tenerife", lo que nos brinda una fotografía del director del periódico con los dos dirigentes de las principales organizaciones empresariales. El motivo del encuentro era informar a los directivos de los medios de comunicación de la futura asamblea que, apelando al "progreso y futuro de Tenerife", se anuncia ya ese día en una página de publicidad de la Cámara de Comercio (26-06-04, pp. 1, 40 y 44).

Apenas un día antes de la reunión, El Día recoge que "Alcaldes socialistas piden la unidad de la Isla en defensa de las Infraestructuras", en una de las pocas ocasiones en las que se le da al PSOE un espacio en la portada. También se destaca que otra asociación de empresarios apoya "sin reservas" la construcción de esta infraestructura (27-06-04, pp. 26 y 49).

La reunión empresarial ocupa la portada del periódico con el llamativo titular "Tenerife en pie", con cuatro páginas de información donde los diferentes representantes políticos y empresariales reclaman la construcción de varias infraestructuras en la isla, y cuyo único espacio para la crítica es una pequeña fotografía de los colectivos ecologistas en el exterior de la asamblea (29-06-04, pp. 1-7).

El protagonismo continúa los días siguientes con noticias sobre los trámites de diversas obras en los puertos de Granadilla y Santa Cruz de Tenerife (30-06-04, p. 42) y con la petición del presidente del Gobierno canario de impulsar consensos para ejecutar las grandes obras de la isla (1-07-04, p. 42). De igual forma se vuelve a dar cobertura al PSOE cuando pide que se "desarrolle al máximo el puerto de Santa Cruz de Tenerife" (207-04, p. 42). Con mucho menos espacio, en la sección de Tenerife, se ve la admisión a trámite de una querella de Greenpeace contra la consejera de Medio Ambiente del Gobierno regional por prevaricación al informar del impacto medioambiental de esta infraestructura (3-07-04, p. 39).

contacto directo, junto al intercambio de roles entre emisores y receptores es un factor fundamental" para los intereses de los organizadores de cualquier evento (Baamonde, 2010). 


\subsection{Constitución de la Asamblea por Tenerife}

El 17 de julio de 2004 se constituye Asamblea por Tenerife, donde diversos colectivos sociales y ecologistas se unen para exigir que las grandes infraestructuras de la isla no causen un daño irreparable al medioambiente. Este grupo de asociaciones, que había protagonizado la opinión contraria al puerto de Granadilla y liderado la recogida de más de 50.000 firmas contra el mismo, recibe una repercusión en El Día bastante elocuente: no existe -ni siquiera se recoge con una breve noticia o comentario-.

La ausencia nada casual de esta información se puede comparar perfectamente con lo ocurrido dos días antes, cuando el periódico recoge en la sección de Tenerife Sur otra información menos novedosa: "Nace una plataforma para exigir las grandes obras". Lo curioso de esta noticia es que abre el periódico como la información principal de la portada cuando en su interior, y con el título "Ciudadanos para el Progreso de Tenerife reivindican las grandes obras", se descubre que es una asociación de ciudadanos del sur de la isla (16-07-04, pp. 18 y 1) que no ha tenido mayor repercusión en fechas posteriores. En contraste, Asamblea por Tenerife, además de agrupar a colectivos que llevan funcionando desde hace años, ha seguido existiendo y realizando diversas acciones incluso después de que la ILP fuera rechazada en el Parlamento regional.

En este mismo día constatamos que la crítica a esta infraestructura es reducida al máximo, relegando a una columna que "El futuro puerto de Granadilla es el peor punto negro, según Greenpeace" (16-07-04, p. 9), mientras que otras obras, de mucha menor envergadura, pero con los vecinos de un barrio de Santa Cruz como protagonistas, tienen otra cobertura bien distinta: "Centenares de vecinos se manifiestan contra el muelle deportivo de Valleseco" (25-07-04, p. 16).

\subsection{Manifestación contra el puerto de Granadilla}

Miles de personas se manifiestan el 27 de noviembre de 2004 contra el proyecto del puerto de Granadilla y otras grandes infraestructuras de la isla. El precedente de la manifestación de Vilaflor, donde más de 150.000 personas recorrieron las calles de Santa Cruz de Tenerife en noviembre de 2002, estaba presente tanto en los asistentes como en la clase política y empresarial de la isla. A la polémica utilización por el Gobierno canario de un avión dedicado a la cartografía para calcular el número de asistentes se suma la tradicional discrepancia sobre dicho número y la repercusión que este acto tendría.

En los días previos a la manifestación, El Día publica varias informaciones sobre el puerto de Granadilla, incluidas mayoritariamente en la sección de Tenerife. Vemos así en portada que "Las obras del puerto de Granadilla se iniciarán en el primer semestre de 2005", aunque acudiendo a su interior, se observa que es el alcalde de Granadilla, según sus estimaciones, el que fija la fecha (16-11-04, pp. 1 y 9). En esa misma noticia, pero con un espacio menor, se recogen también algunas posturas contrarias al proyecto. 
Durante los siguientes días se publican varias informaciones que tenían como fuente la Autoridad Portuaria y al presidente de Coalición Canaria, en las que se dice que "La Autoridad Portuaria acepta el puerto por prioridad económica", en referencia al recorte en sus dimensiones pero recordando las limitaciones del de la capital: "La Autoridad Portuaria afirma que hay tráficos que Santa Cruz no puede atender" (19-11-04, pp. 1 y 10; y 20-11-04, p. 9). En clave política, el presidente de Coalición Canaria afirma en una entrevista que "con el puerto de Granadilla gana la Isla", mientras que en la misma edición se recoge una conferencia del economista Ramón Tamames, quien destaca la importancia del puerto siempre y cuando se haga con "cuidado", aunque desde el periódico sólo se resalta en un ladillo y en la portada la frase de que sería "bastante necio" oponerse a esta infraestructura (21-11-04, pp. 1, 16, 17 y 50).

Ya los días inmediatamente anteriores a la manifestación se insiste en las fuentes oficiales, cuando afirman en portada y con un amplio espacio en su interior que "Madrid aclara las dudas sobre Granadilla a la UE" (24-11-04, pp. 1 y 10) y que "Sale a licitación pública las obras del abrigo del nuevo dique de Granadilla" (25-11-04, pp. 1 y 10). A esto hay que añadir la publicidad insertada esos días por la Autoridad Portuaria destinada a fortalecer la defensa del puerto y a contrarrestar los efectos de la inminente manifestación: una página completa destacando el amplio consenso y bajo el lema "Tenerife y Canarias ganan con el nuevo sistema portuario de Santa Cruz y Granadilla" (25 y 26-11-04, pp. 29).

El mismo día de la manifestación se publica el reportaje "El puerto de Granadilla, el debate entre el ecologismo y necesidad", donde se hace un repaso cronológico a este proyecto (27-11-04, p. 10). Más significativa es la portada del día siguiente a la manifestación: "El puerto de Granadilla no se parará". En su interior, dentro de la noticia "Una marea de protestas", se destaca que la "propia dispersión ideológica de la marcha amenazó con disgregar el sentido de la convocatoria". También leemos ese día que "El Gobierno de Canarias sostiene que el puerto de Granadilla es "necesario", donde el Gobierno, en un comunicado, como así se señala expresamente, ofrece su opinión sobre la manifestación. Lo más relevante es que esta información es la que abre el periódico, cuando parece evidente que debiera haber sido la noticia principal (la manifestación) y no la reacción (opinión del Gobierno en un comunicado) la que ocupara el espacio principal (28-11-04, pp. 1, 4 y 6).

Días después de la manifestación vuelve el protagonismo gubernamental con la noticia de que "[El presidente canario Adán] Martín dice que si el puerto de Granadilla fuera perjudicial no defendería esta obra" (30-11-04, p. 10). La entrevista al presidente sólo es significativa por su respaldo a un proyecto cuestionado que, en palabras de la máxima autoridad política del archipiélago, supone un beneficio para el conjunto de la población. Con menor espacio, el periódico publica pequeñas notas bajo la entrevista recogiendo opiniones contrarias al proyecto.

Con el aparente intento de ofrecer un debate más amplio y no marcado por la actualidad diaria, el día 5 se publica una entrevista/debate colectiva con el titular "El puerto de Granadilla sigue vivo” y un antetítulo “¿Sirvió para algo la manifestación?”, demostrando 


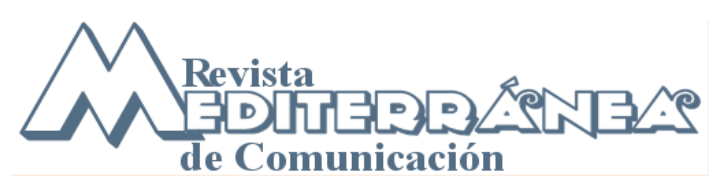

con estos titulares una postura crítica con la manifestación, que luego, en la entradilla del texto firmado por los periodistas, se constata al calificar la manifestación como un "gesto" (5-11-04, pp. 4 y 6$)$.

\subsection{Rechazo parlamentario a la Iniciativa Legislativa Popular}

El 13 de enero de 2005 el Parlamento de Canarias rechaza tramitar la Iniciativa Legislativa Popular de más de 50.000 firmas para crear un espacio protegido donde se quería construir el puerto de Granadilla. El mismo día en el que se debate, el periódico publica que "Medioambiente aclara que sí emitió un informe sobre la reserva natural de Granadilla" (13-01-05, p. 35). Al día siguiente, ya con el rechazo a la tramitación parlamentaria, la ILP sí aparece en portada, cuando su registro en la Cámara sólo ocupó un pequeño espacio en la última página de Economía. Así, se recoge que "El Parlamento no admite que se pare el puerto de Granadilla" -con una referencia en portada- y que "La Cámara rechaza la iniciativa popular para proteger el litoral de Granadilla". Fruto del debate surge otra iniciativa que es igualmente recogida por el periódico: "El Parlamento insta al Estado a impulsar las infraestructuras en el Archipiélago" (14-01-05, pp. 1, 33 y 34).

Las reacciones a la malograda iniciativa popular llegaron un día después, con una portada protagonizada por la clase empresarial: "La Cámara de Comercio corrige a Antonio Castro", en referencia al consejero de Infraestructuras y las obras pendientes de ejecución, incluyendo el puerto. También se recoge una entrevista al presidente de la Asociación de la Construcción de Santa Cruz de Tenerife, que afirma que "se está dando un fenómeno de extremismo medioambiental" (15-01-05, pp. 1, 10 y 36).

En línea con los reproches entre instituciones y administraciones, en una entrevista con el presidente del Cabildo de Tenerife, Ricardo Melchior, se señala que existe una "inhibición del Gobierno" (16-01-05, pp. 22 y 23). Como contraposición, días después, una entrevista al presidente del Gobierno de Canarias, Adán Martín, es titulada criticando a la institución insular: "Aquí el Cabildo y los alcaldes cuestionan más las obras", motivo suficiente para abrir el periódico y luego extenderse en el interior (23-01-05, pp. 40 y 41).

\section{La opinión de una obra}

Una de las razones por las que se escoge el periódico El Día para hacer este estudio es la publicación de un comentario diario que, en la práctica, se presenta como un editorial que en su versión dominical llega a ocupar una página entera. La postura del diario o de su editor con respecto a determinados temas de actualidad encuentra aquí el espacio correcto, lo que nos permite, además, contrastar el tratamiento informativo al proyecto del puerto de Granadilla con la línea ideológica y los intereses de este periódico, oficialmente reflejados en sus comentarios.

Semanas antes de que se presentara en el Parlamento regional la Iniciativa Legislativa Popular contra el proyecto, los editoriales del periódico ya manifiestan una posición 
claramente favorable a la construcción del puerto y afín, por tanto, a los intereses económicos y empresariales, así como al de determinados partidos políticos. Esta postura, absolutamente respetable, se acompaña, sin embargo, con descalificaciones como las "puñaladas" del Ministerio de Medioambiente o, más concretamente, el "capricho de ciertos enajenados de allí o por la torpeza de señalados políticos de aquí". Según este editorial, es necesario dejarse aconsejar por "los verdaderos expertos y por el pueblo, que sí quieren este puerto con la capacidad pactada y no el de 350 metros" (4-04-04, p. 3).

Al día siguiente de la presentación de esta iniciativa popular se hace una afirmación que, susceptible de muchas interpretaciones, explica la postura de algunos actores con respecto al puerto: "Como se sabe, donde se halla el poder económico se sitúa también el político". En este mismo texto se señala que "saludamos y compartimos de la 'pe' a la 'pa' las declaraciones publicadas ayer por la CEOE" y se añade que "no nos cansaremos de exigir a las autoridades tinerfeñas que despierten de una vez por todas y abandonen esa adocenada actitud, que tan perjudicial está resultando para las intereses del territorio que representan" (21-04-04, p. 7).

En las fechas cercanas al foro de empresarios se encuentran editoriales que alaban la gestión empresarial con titulares como "Nace el firme ¡Basta ya! de Tenerife" y otros como el "sí rotundo al progreso y futuro de Tenerife", referidos a la construcción de nuevas infraestructuras, detallando y defendiendo cada una de las propuestas empresariales. En estos editoriales también se deja clara la opinión sobre los que critican el puerto: "Respetamos el ecologismo puro, no mínimo, revoltoso y novelero, ni el de surfistas y un par de godos/as ${ }^{7}$ sospechosos, ni espurios ni subvencionados" (29-06-04, p. 7; 30-06-04, p. 5; y 4-07-04, p. 3).

Caso más extraño son los editoriales publicados en torno a la constitución de la Asamblea por Tenerife ya que, pese a no informar de este hecho, sin embargo sí que se opina del mismo con algunas frases: "resulta sospechoso" que el ecologismo se centre en Tenerife con organizaciones que nacieron en Gran Canaria y "majaderos que siguen oponiéndose por sistema, o vaya usted a saber por qué a todo lo que significa que Tenerife progrese, mientras permanecen callados cuando se trata del desarrollo de Las Palmas". Todos estos reproches, habituales en los comentarios de la dirección del periódico, se recogen en editoriales con títulos muy significativos: "El progreso no se puede detener" y "Ecologistas equivocados e intransigentes" (17-07-04, p. 5 y 18-07-04, p. 3).

En el mes de noviembre, a medida que se acerca la manifestación contra el puerto de Granadilla, se publican varios editoriales que critican continuamente a los "falsos ecologistas" o "histéricos", entre otros términos descalificativos que, además, se acompañan con las adyacentes columnas de opinión de Andrés Chávez, que añade el término "plataformeros". Semanas después se exige que haya un "equilibrio real", en referencia al reparto de inversiones entre islas, y se alaba la figura de las "fuerzas vivas",

\footnotetext{
${ }^{7}$ Término despectivo utilizado en Canarias para referirse a las personas naturales del resto de España.
} 
término muy simbólico para referirse a los impulsores de los grandes proyectos de la isla, es decir, a los empresarios (días 4, 6, 8, 14, 28 y 31 de diciembre de 2004 y 9 de enero de 2005).

\section{Consideraciones finales}

Somos conscientes de que la construcción de un puerto industrial en una isla es un elemento de una gran trascendencia, susceptible de ser analizado con un enfoque económico, social, político o medioambiental, según el aspecto concreto que se quiera destacar. Sin embargo, como sucede con gran parte de las infraestructuras, vemos que la mayor parte de su protagonismo se ha quedado en el ámbito local, donde precisamente se produce el debate político social, quedando los datos económicos o medioambientales como argumentos de las diferentes partes enfrentadas.

El proyecto del puerto, como ha ocurrido con otras infraestructuras, se ha convertido en polémico por ser un punto de fricción entre dos modelos de vida, dos concepciones enfrentadas con un evidente matiz ideológico. Vemos así cómo organizaciones empresariales y partidos políticos conservadores defienden este proyecto, mientras que organizaciones ecologistas, asociaciones y partidos de izquierda son los que se manifiestan en contra, independientemente de las excepciones que podemos encontrar justificadas en muchos casos en unos intereses particulares.

Sin embargo, más allá de las posturas enfrentadas, lo interesante es que el debate se circunscribe al ámbito local, haciendo uso arbitrario de los aspectos económicos y medioambientales. El Día demuestra aquí su nulo interés por ver en el puerto un asunto medioambiental, ubicando siempre toda la información en las secciones de Tenerife y Economía -nunca aparece en Sociedad-, donde políticos y organizaciones empresariales tienen un puesto preferente y, por tanto, ocupan el protagonismo del debate. Sólo así podemos entender la ocultación sistemática de las quejas medioambientales o la publicación íntegra del discurso de los promotores del puerto, favoreciendo los intereses del medio y las "fuerzas vivas" que apoyan el proyecto.

Esta marginación de lo ambiental no es fruto de una improvisación o un error, ya que de forma continua y reiterada se brinda un tratamiento positivo y abundante a los que piden la construcción del puerto frente al tratamiento negativo y casi inexistente a los que defienden el paraje natural. Una cobertura nada casual en vista de la línea editorial del periódico, donde la defensa del proyecto se lleva hasta sus máximos extremos, exaltando la relevancia histórica de los líderes empresariales y despreciando mediante continuos insultos cualquier oposición al puerto.

Así, del análisis de lo publicado vemos conclusiones similares a los ejemplos expuestos en los apartados teóricos, como el desinterés por buscar expertos u opiniones científicas y académicas que den una visión ajena a los protagonistas de la disputa, la no existencia de secciones o periodistas que escriban sobre medioambiente o la presión de los poderes empresariales para frenar las críticas medioambientales. Sin embargo, es necesario 
destacar algunos elementos concretos que nos muestran la sistemática marginación realizada por la dirección del medio y sus redactores.

-No publicar informaciones contrarias al puerto o hacerlo en espacios muy reducidos, como la constitución de Asamblea por Tenerife o la presentación de la ILP en defensa de la Reserva Natural.

-Recurrir a expertos que defienden el puerto mediante datos y estudios, especialmente económicos, y no recoger la opinión de otros que, también desde la economía o la biología, se oponen al proyecto.

-Apropiarse de conceptos como progreso, desarrollo o bienestar que en manos de la dirección -editorial- o las fuentes interesadas -políticos y empresariosminimizan u omiten definiciones ligadas al medioambiente.

-Considerar como hechos contrastados afirmaciones de los defensores del puerto y asegurarse que las críticas queden personalizadas: "El futuro puerto de Granadilla es el peor punto negro, según Greenpeace" frente "El puerto de Granadilla generará 20.000 empleos" o "El progreso económico de Tenerife se frenará si no mejoran sus puertos".

-Neutralizar la repercusión positiva de un acontecimiento contrario al puerto dándole más peso a la reacción de los partidarios: tras la manifestación contra el puerto se abrió el periódico con la reacción del Gobierno.

-Reforzar la jerarquía del periódico al resaltar una postura en defensa del puerto aunque eso implique llevar a titulares o portadas aspectos secundarios para el redactor o el jefe de sección correspondiente.

- Apelar al liderazgo -o discriminación- de Tenerife en Canarias frente a Gran Canaria como forma de garantizar un apoyo de una opinión pública todavía lastrada por el pleito insular.

Es evidente que todas estas características, al margen de la ya señalada ubicación de la información en secciones de Economía o Local, reflejan una decisión activa del periódico, que va reculando su defensa del puerto, desde la censura a los colectivos que se oponen al mismo, hasta su forzada inclusión en el diario cuando alcanzan gran notoriedad, pero optando aquí por minimizar al máximo su repercusión al ubicarlos en otras secciones o en pequeños espacios.

Dirección y redacción participan bien de forma voluntaria u obligada por la censura interna o autocensura en la negación del periodismo medioambiental. Si en el caso de la dirección vemos reflejada en fotografías -el editor aparece con los líderes empresarialesy editoriales el interés por congratularse con sectores que, por otra parte insertan publicidad de forma constante, podemos entender que en el caso de los redactores es la estrecha relación que hay con las fuentes en el ámbito local, lo que les lleve a la 


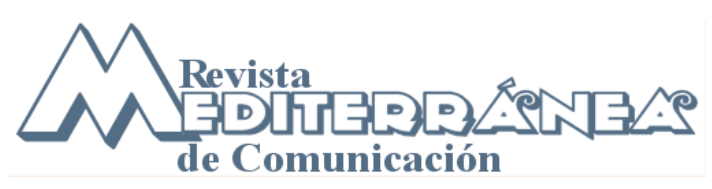

manipulación y servilismo a los cargos públicos y privados en pos de su propio beneficio o de su medio.

En un escenario ideal, el periodista hubiera informado de las consecuencias positivas y negativas que la construcción del puerto tendría para la población de la isla, incluyendo obviamente el espacio físico donde habita. Sin embargo, lo ideal queda lejos de la imagen reflejada del proyecto, donde casi no existe un problema medioambiental que amenace el objetivo de llevar al lector hacia una posición favorable al puerto.

Así, el periodismo medioambiental se configura como un elemento marginado cuando los intereses políticos y empresariales están en juego, reforzados por la estrecha relación que hay en el ámbito local. $Y$ aunque no podemos afirmar que la sola presencia de este periodismo nos aseguraría que medios y periodistas, condicionados por el establishment local, hicieran un tratamiento equilibrado de la información, sí creemos que este periodismo, plasmado en una sección, periodista o información, ofrecería al lector modelos de vida donde el desarrollo no implique una ilimitada explotación del planeta.

\section{Bibliografía}

Baamonde Silva, Xosé Manuel (2010): "Los Gabinetes de Comunicación del sector ferial ante la crisis financiera. Perfiles, acciones y estrategias", en Miguel Hernández Communication Journal, 1, páginas 78 a 98. Universidad Miguel Hernández, UMH (ElcheAlicante). Recuperado el 20 de marzo de 2010 de:

http://mhcj.es/2010/03/09/baamonde/

Elías, C. (2002): "Periodismo especializado en medio ambiente: el caso Doñana como paradigma de manipulación informativa”. Revista Latina de Comunicación Social, 47. Recuperado el 22 de octubre de 2009 de:

www.ull.es/publicaciones/latina/2002/latina47febrero/4708elias.htm

León Duarte, Gustavo Adolfo (2010): "Estrategias, posiciones y prácticas científicas en la enseñanza y la Investigación de la Comunicación en América Latina", en Miguel Hernández Communication Journal, 1, páginas 53 a 77. Universidad Miguel Hernández, UMH (Elche-Alicante). Recuperado el 20 de marzo de 2010 de: http://mhcj.es/2010/01/24/gustavo-leon-duarte/

Lorente, J. I. et al (2009): "La construcción mediática de lo ecológico. Estrategias discursivas en la información de actualidad”. Revista Latina de Comunicación Social, 64, páginas 315 a 327 . Recuperado el 22 de octubre de 2009 de:

http://www.revistalatinacs.org/09/art/26_825_49_ULEPICC_05/Lorente_et_al.html

McQuail, D. (2000): Introducción a la teoría de la comunicación de masas. 3ª edición revisada y ampliada. Barcelona, Buenos Aires, Paidós. 
Montaño, M. (1999): "Periodismo ambiental en Canal Sur". Revista Latina de Comunicación Social, 16. Recuperado el 22 de octubre de 2009 de:

http://www.ull.es/publicaciones/latina/a1999iab/100A/montano.html.

Piñuel Raigada, J. L. y Gaitán Moya, J. A. (1995): Metodología general: Conocimiento e investigación en la comunicación social. Madrid, Síntesis.

Sanmartí, J. M. (2003): "Periodismo especializado, el nexo entre conocimiento y sociedad" (pp. 7-28) y "Periodismo de la salud y el medio ambiente" (pp. 127-134) en De Ramón, Manuel (coordinador): 10 lecciones de periodismo especializado. Madrid, Fragua.

Seijas Candelas, L. (2003): Estructura y fundamentos del periodismo especializado. Madrid, Universitas.

Van Dijk, T. A. (1993): "El estudio interdisciplinario de las noticias y el discurso" en Metodologías cualitativas de investigación en comunicación de masas (Jensen K. B. y Jankowski, N. W. editores) Barcelona, Bosch.

--- (2003): "La multidisciplinariedad del análisis crítico del discurso: un alegato a favor de la diversidad" (pp. 143-177) en Wodak, Ruth y Meyer, Michael (compiladores): Métodos de análisis crítico del discurso. Barcelona, Gedisa.

--- (2006): “Discourse and manipulation" (pp. 359-383) en Discourse and society. Volúmen 17.

Vliegenthart, R. et al (2009): "Communicating the Environment" en Annual meeting of the International Communication Association, New York.

Wodak, R. (2003): "De qué trata el análisis crítico del discurso (ACD). Resumen de su historia, sus conceptos fundamentales y sus desarrollos" (pp. 17-34) en Wodak, Ruth y Meyer, Michael (compiladores): Métodos de análisis crítico del discurso. Barcelona, Gedisa.

Yanes Mesa, J. A. (2005): Metodología de la historia de la comunicación social en Canarias: la prensa y las fuentes. Tegueste, Baile del Sol.

Zorrilla, M. (1996): "La información en la prensa diaria" (pp. 51-63) en I Congreso nacional de periodismo ambiental. Asociación de periodistas de información ambiental. Madrid. 